\title{
Predictors of Stress and Coping among Nursing Students in the College of Nursing at University of Hail, Saudi Arabia
}

\author{
Hamdan Albaqawi* \\ Assistant Professor, College of Nursing, University of Hail, Kingdom of Saudi Arabia
}

Received Date: March 30, 2017 Accepted Date: April 13, 2018 Published Date: April 19, 2018

Citation: Hamdan Albaqawi (2018). Predictors of Stress and Coping among Nursing Students in the College of Nursing at University of Hail, Saudi Arabia. POJ Nurs Prac Res 2 (1): 1-7.

*Corresponding Author: Hamdan Albaqawi, PhD, Assistant Professor, College of Nursing, University of Hail, Kingdom of Saudi Arabia, Email: dr-hamdan@outlook.com

\begin{abstract}
Background: Faced with a multiple roles from the demands of classroom and clinical area, nursing students are predisposed to stressful experience. As panacea thereof, an implementation of applicable coping intermediations to assist in the management of stress in nursing students is a pressing need.

Methods: This research employed a cross-sectional analytical design using regression analysis in probing the association of the demographic variables affecting the perceived stress and coping among nursing students in the north-western region of Saudi Arabia. There were 200 nursing students (38\% response rate) who participated in the study. The researcher used the Perceived Stress Scale by Cohen and COPE inventory by Carver.

Results: The data suggests that majority of the respondents $(61 \% ; n=200)$ perceived a moderate amount of stress $(20.52 \pm 7.59)$ as nursing students. In response to stress, the Saudi nursing students utilized emotionfocused coping strategy in the context of religious practices $(3.53 \pm 0.31)$. Regression analysis, on the association of demographic variables to perceived stress, identified that the female nursing students $(60 \% ; n=200)$ have heightened perception of stress $\left(p=.000 ; r^{2}=.136\right.$; Coefficient=3.633). Meanwhile, in terms of the demographic variables to coping, results revealed that married $(74.5 \% ; n=200)$ students are more likely to cope negatively in response to stress $\left(p=.025 ; r^{2}=.061 ; B=-8.324\right)$, together with students belonging to the regular program $(73.5 \%$; $\mathrm{n}=200)$ with poor coping responses as well $\left(\mathrm{p}=.015 ; r^{2}=.061 ; \mathrm{B}=-16.160\right)$.
\end{abstract}

Conclusion: Female gender can have an influence with the perceived stress of the nursing students. Moreover, married marital status and regular nursing program may have a high probability of affecting the coping mechanism of the nursing students negatively. To validate the conclusion, other factors such as clinical competence, selfesteem, time management abilities, family finances and quality of student life maybe sources of stress and can be considered in further assessing coping responses to stress in later studies. Further studies are recommended on other branches of education such as engineering, education and arts to evaluate similarity or contrast of results. It is important to explore the effect of stress on students and thoroughly assess their capacity in responding to stress. Stress management activities are a must to help achieve positive coping behaviors among nursing students.

Keywords: Coping, Nursing, Nursing Students, Perceived Stress.

\section{Introduction}

Stress is an unavoidable experience resulting to several changes in a student's life [1]. Alterations in the physical, psychological, and emotional aspects may happen which consequently results in poor academic performance [2]. As panacea thereof, an implementation of applicable coping intermediations to assist in the management of stress in nursing students is a pressing need. Stress is defined as a state of disturbed homeostasis evoked by the physiological and behavioral adaptive responses. The body's response to stress depends on the vulnerability of the body to the stressor, ability of the body to cope with the stressor

Copyright: ${ }^{\circledR} 2018$ Hamdan Albaqawi. This is an open-access article distributed under the terms of the Creative Commons Attribution License, which permits unrestricted use, distribution, and reproduction in any medium, provided the original author and source are credited. 
and the threat to homeostasis [3]. While it is a complex occasion that happens with the interaction of an individual against their internal and external environments, this leads to changes in the physical, mental, emotional, and behavioral aspects [4]. Of interest, it is considerably important that stress varies and diverse at times in life so much so with the nursing students as they have been holistically affected due to their multiple roles [5]. Stress in nursing arises from the theory-to-practice, wherein nursing students experience stress both in academics and clinical practice [6]. In this case, coping mechanism will come into play. Coping mechanism is the capacity to face and adapt to stressful situations. It is an ability that allows people to react to behavior, thoughts and emotions caused by such events [7].

Stress and coping styles have been investigated by the numerous researchers, and it explores variables that lead to understanding stress and coping mechanisms [8-11]. Studies on stress and coping are widely prevalent, and there needs to recognize predictors which serve as a keys to address the problem. The study of Wolf, Warner and Ross reported that history of depression, year in the program, emotional support, and selfesteem are predictors of stress for both the accelerated and generic groups [12]. The coping strategies used by both groups included positive thinking and social support. Meanwhile, Pulido-Martos Augusto-Landa and Lopez-Zafra found out that the courses and the academic year which the nursing students are enrolled has with influence in the coping strategies that they would select while they deal with stress [13]. In particular, the second-year student nurses found to be utilizing emotional strategies as more than senior nurses or students who are registered in advanced adult nursing courses. On the other hand, Rajesh Kumar investigated on the levels of stress and coping strategies of nursing students and found out that majority of nursing students incline to healthy coping strategies [14]. In Rajesh Kumar's study, the seeking diversion was the most common coping strategy while the least is seeking professional support. While there are prevalent studies on stress and coping strategies worldwide, little research is available on stress levels and coping styles of nursing students in Saudi Arabia. From the researcher's knowledge, only the study of Hamaideh, Al-Omari, and Al-Modalla, and Alsaqri have investigated the phenomenon $[15,16]$. Hamaideh, Al-Omari, and Al-Modalla found that clinical training has been recognized as a stressful experience for nursing students. In Alsaqri's study, it was found out that nursing students experienced a high level of stress, and the most common coping strategy utilized by the students was problem solving, while avoidance was the least frequently used one. Nursing, as an undergraduate degree, in north-western Saudi Arabia started in 2011. Its' initiation was through the efforts of the Kingdom of Saudi Arabian government to increase the percentage of Saudi nurses in the nursing workforce [17].

While claims on insufficient data about stress and coping strategies' effects on academic performance among Arab students exist, this current research is of significance [18]. Generally, this research determines the levels of stress and coping strategies among nursing students. Specifically, it aims to determine the demographic variables of the nursing students that may have an effect on their level of stress, and coping styles.
The results of this study are of importance as the levels of stress and coping styles of the nursing students may interfere with their health and academic outcomes. As such, the development coping and stress management activities may be proposed in aiding students towards progress in their quality of life.

\section{Methods}

The study employed a quantitative-cross-sectional approach, and analytical design using linear multiple regression analysis in investigating the level of stress and coping styles among nursing students in north-western Saudi Arabia. There were 200 nursing students (38\% response rate) who participated in the study. The study was conducted in the University of Hail during the second semester of academic year 2017-2018.

The study made use of three self-report tools: (1) Demographic profile consisting of age, gender, program, civil status and gradepoint-average (GPA); (2) Perceived Stress Scale (PSS); (3) Coping Orientation to Problems Experienced (COPE).

This study utilized the Perceived Stress Scale (PSS), developed by Dr. Sheldon Cohen. It is a prevalent tool for psychological stress measurement [19]. The PSS is designed to measure the appraisal degree of individuals in stressful situations in their lives and to some degree evaluate on how they view their life experiences as unpredictable, uncontrollable, and overloaded during the previous month [20]. The PSS version used has 10 items based from factor analyzed data [21]. Items were rated using a 5-point Likert scale with corresponding verbal interpretations: (0) Never; (1) Almost never; (2) Sometimes; (3) Fairly often; and (4) Very often. Cronbach's Alpha of the PSS-10 in this study was .709. However, different studies, where the PSS-10 was used, obtained a reliability test of $>.70$ [22-25]. Level of stress was classified as: low stress (0-13); moderate stress (14-26); high stress (27-40).

To find out the coping responses of the nursing students, the Coping Orientation to Problems Experienced (COPE) inventory was used. The tool was developed by Dr. Charles Carver, to determine the response of people when confronted with difficult or stressful events in their lives [26]. The COPE inventory has 60 items divided into 15 scales: positive reinterpretation and growth, mental disengagement, focus on and venting of emotions, use of instrumental social support, active coping, denial, religious coping, humor, behavioral disengagement, restraint, use of emotional social support, substance abuse, acceptance, suppression of competing activities and planning [26]. Items were rated using a 4-point Likert scale with corresponding verbal interpretations: (1) I usually don't do this at all; (2) I usually do this a little bit; (3) I usually do this a medium amount; (4) I usually do this a lot. Cronbach's alpha of the COPE inventory was computed at .735. Verbal interpretations used in the classification of coping responses used by the nursing students were: (1-1.75) never use; (1.76-2.51) almost never; (2.52-3.27) almost every time; (3.28-4.00) frequently used.

\section{Data Collection}

Data was gathered in February 2018 until March 2018 through a self-administered questionnaire. Data collection was done through Google-electronic forms in English and acquired one 
week after the major examination. Before collection, the researcher provided adequate information, such as the aim of the study, their expected participation, the time required for participation, privacy of data, and their right to refuse participation or discontinue their participation for any reason without any consequences to their part. In this study, all of the items have been answered by the respondents according to their convenience. The researcher waited for a week then data was collated.

\section{Data Analysis}

Data analyses were performed using the SPSS version 22.0 [27]. Descriptive statistics were used to describe the demographic characteristics of the nursing students. The GPA in this study, was categorized as high (>2.36) and low (<2.36). Multiple linear regression analysis was used to determine the likelihood of the demographic variable to affect the perceived stress and coping of the nursing students. All statistical analyses were performed at a .05 level of significance.

Results

Majority of the respondents were below 26 age group (74.5\%; $\mathrm{n}=200)$ and were female $(60 \% ; n=200)$. As to civil status, most were married (74.5\%; $n=200)$. A large number were from the regular nursing program $(73.5 \% ; n=200)$ and has a relatively low grade-point-average (GPA) of below 2.36 (52\%) compared to those with high GPA above 2.36 (48\%; n=200) (Table 1).

\section{Discussions}

Results showed that the nursing students perceived their stress level as moderate to high. Based from the result, an overall stress of $20.52 \pm 7.57$ was computed which pertained to moderate

Table 1: Demographic Profile of Respondents

\begin{tabular}{|l|l|c|c|}
\hline Attributes & & $\mathbf{n}$ & $\%$ \\
\hline Age (Years) & $\geq 26$ & & \\
\hline & $<26$ & 51 & 25.5 \\
\hline Gender & Female & 149 & 74.5 \\
\hline & Male & 80 & 60 \\
\hline Civil Status & & & 40 \\
\hline & Married & 149 & 74.5 \\
\hline & Single & 51 & 25.5 \\
\hline Program & & & \\
\hline & Bridging & 53 & 26.5 \\
\hline & Regular & 147 & 73.5 \\
\hline GPA & & & \\
\hline & $>2.36$ (high) & 96 & 48 \\
\hline & $\leq 2.36$ (low) & 104 & 52 \\
\hline
\end{tabular}

Table 2 shows that majority of the nursing students were moderately stressed $(61 \%$; $n=200)$ while $22.5 \%$ of them were highly stressed. An overall stress level of $20.52+7.59$ was noted.

Table 2: Perceived Stress of the nursing students

\begin{tabular}{|l|c|c|c|}
\hline Level of Stress & $\mathbf{n}$ & $\%$ & mean \\
\hline Low Stress & 33 & 16.5 & $8.67 \pm 3.95$ \\
\hline $0-13$ & 122 & 61 & $20.11 \pm 3.56$ \\
\hline Moderate Stress & & \\
\hline $14-26$ & 45 & 22.5 & $30.33 \pm 2.91$ \\
\hline High stress & $20.52 \pm 7.59$ \\
\hline $27-40$ & &
\end{tabular}


Most of the nursing students apply problem-focused coping response in the form of planning $(3.08+0.018)$ with a verbal interpretation of almost every time. In terms of emotion-focused coping responses, religious coping (3.53+0.31) was frequently used while denial $(2.35+0.03)$ was least utilized. Less useful coping responses never used was substance abuse (1.14+0.08) (Table 3).

Table 3: Coping response of the nursing students using COPE inventory

\begin{tabular}{|c|c|c|}
\hline Scales & Mean/SD & Interpretation \\
\hline \multicolumn{3}{|l|}{ Problem-Focused } \\
\hline Use of instrumental social support & $2.76 \pm 0.07$ & almost every time \\
\hline Active coping & $2.91 \pm 0.05$ & almost every time \\
\hline Restraint & $2.73 \pm 0.04$ & almost every time \\
\hline Suppression of competing activities & $2.73 \pm 0.045$ & almost every time \\
\hline Planning & $3.08 \pm 0.018$ & almost every time \\
\hline \multicolumn{3}{|l|}{ Emotion-Focused } \\
\hline Positive reinterpretation and growth & $3.21 \pm 0.06$ & almost every time \\
\hline Denial & $2.35 \pm 0.03$ & almost never \\
\hline Religious coping & $3.53 \pm 0.31$ & frequent \\
\hline Use of emotional social support & $2.38 \pm 0.05$ & almost never \\
\hline Acceptance & $2.73 \pm 0.05$ & almost every time \\
\hline \multicolumn{3}{|c|}{ Other less commonly used coping response } \\
\hline Mental disengagement & $2.67 \pm 0.12$ & almost every time \\
\hline Focus on and venting of emotions & $2.41 \pm 0.05$ & almost never \\
\hline Behavioral disengagement & $1.92 \pm 0.02$ & almost never \\
\hline Substance abuse & $1.14 \pm 0.08$ & never use \\
\hline Humor & $2.1 \pm 0.06$ & almost never \\
\hline Overall mean coping response & $154.56 \pm 20.39$ & \\
\hline
\end{tabular}

Table 4 shows linear multiple regression analysis of the PSS with the demographics as the predictors. Among the demographic variables, results revealed that being female most likely influence the perceived stress of the nursing students ( $p=.000 ; R^{2}=.136$; beta $=3.633$ ) .

Table 4: Regression Analysis for Demographic Variables and Perceived Stress of the nursing students

\begin{tabular}{|l|c|c|c|c|c|c|c|}
\hline & \multicolumn{2}{|c|}{$\begin{array}{c}\text { Unstandardized } \\
\text { Coefficients }\end{array}$} & $\begin{array}{c}\text { Standardized } \\
\text { Coefficients }\end{array}$ & $\mathrm{t}$ & Sig.(p=<.05) & \multicolumn{2}{c|}{$\begin{array}{c}95 \% \text { Confidence } \\
\text { Interval for B }\end{array}$} \\
\cline { 1 - 4 } & B & Std. Error & Beta & & & $\begin{array}{c}\text { Lower } \\
\text { Bound }\end{array}$ & $\begin{array}{c}\text { Upper } \\
\text { Bound }\end{array}$ \\
\hline Age $\geq 26$ & -0.966 & 1.846 & -0.074 & -0.523 & .601 & -4.606 & 2.675 \\
\hline Age <26 & .958 & 1.854 & .073 & .517 & .606 & -2.698 & 4.614 \\
\hline Male & -1.720 & 3.931 & -.040 & -.438 & .662 & -5.251 & -2.015 \\
\hline Female & 3.633 & .820 & .311 & 4.429 & .000 & 2.015 & 5.251 \\
\hline Bridging & .257 & 1.763 & .020 & .146 & .884 & -3.221 & 3.734 \\
\hline Regular & -.272 & 1.770 & -.021 & -.154 & .878 & -3.763 & 3.220 \\
\hline High GPA & 1.478 & 1.445 & .129 & 1.023 & .308 & -1.372 & 4.328 \\
\hline Low GPA & 1.697 & 1.296 & .164 & 1.309 & .192 & -.860 & 4.254 \\
\hline Single & 1.608 & 0.977 & .126 & 1.645 & .102 & -.320 & 3.535 \\
\hline Married & -1.589 & .996 & -.121 & -1.595 & .112 & -3.554 & .376 \\
\hline Divorced & -2.333 & 2.594 & -.064 & -.899 & .370 & -7.448 & 2.783 \\
\hline$R^{2}=.136 ;$ Std. Error of the Estimate= 5.429 & & & & \\
\hline
\end{tabular}


Table 5 shows that nursing students who were married most probably coped lesser $(p=.025 ;$ beta $=-8.324)$. Results revealed a high likelihood of nursing students enrolled in the regular program to cope negatively $(p=.015$; beta=-16.160).

Table 5: Regression Analysis for Demographic Variables and Coping of the nursing students

\begin{tabular}{|c|c|c|c|c|c|c|c|}
\hline & \multicolumn{2}{|c|}{$\begin{array}{l}\text { Unstandardized } \\
\text { Coefficients }\end{array}$} & \multirow{2}{*}{$\begin{array}{c}\text { Standardized } \\
\text { Coefficients }\end{array}$} & \multirow[t]{2}{*}{$\mathbf{t}$} & \multirow[t]{2}{*}{ Sig. $(p=<.05)$} & \multicolumn{2}{|c|}{$\begin{array}{l}\text { 95\% Confidence } \\
\text { Interval for B }\end{array}$} \\
\hline & $B$ & $\begin{array}{l}\text { Std. } \\
\text { Error }\end{array}$ & & & & $\begin{array}{l}\text { Lower } \\
\text { Bound }\end{array}$ & $\begin{array}{l}\text { Upper } \\
\text { Bound }\end{array}$ \\
\hline Age $\geq 26$ & 0.045 & 3.316 & 0.001 & 0.013 & .989 & -6.494 & 6.584 \\
\hline Age $<26$ & 10.178 & 6.868 & .218 & 1.482 & .140 & -3.369 & 23.725 \\
\hline Male & 0.929 & 2.949 & .022 & 0.315 & .753 & -4.887 & 6.746 \\
\hline Female & .119 & 3.040 & .003 & .039 & .969 & -5.876 & 6.115 \\
\hline Bridging & 3.814 & 3.264 & .083 & 1.169 & .244 & -2.622 & 10.250 \\
\hline Regular & -16.160 & 6.559 & -.351 & -2.464 & .015 & -29.097 & -3.223 \\
\hline High GPA & -3.982 & 5.354 & -.098 & -.744 & .458 & -14.542 & 6.578 \\
\hline Low GPA & -.512 & 4.804 & -.014 & -.107 & .915 & -9.987 & 8.962 \\
\hline Single & 5.781 & 3.193 & .128 & 1.811 & .072 & -0.515 & 12.077 \\
\hline Married & -8.324 & 3.691 & -.178 & -2.255 & .025 & -15.605 & -1.043 \\
\hline Divorced & -.723 & 9.611 & -.006 & -.075 & .940 & -19.679 & 18.233 \\
\hline
\end{tabular}

stress level. This also means that on the perceived stress scale, majority of the Saudi nursing students achieved a total score equivalent to moderate stress. This may imply that Saudi nursing students experience the same amount of stress as with other nationalities. The results of the study corroborated with the study conducted by Saleh, where stress factors were evaluated among French college students [28]. It was found that majority of the college students suffered from psychological stress, anxiety and depression. Low self-esteem, little optimism and low sense of self-efficacy was also noted in the study. Further, fear of failure, clinical incompetence, problematic relationships and problematic time management were identified as major stressors $[12,29]$.

Meanwhile, the finding of this investigation suggests that Saudi nursing students rely on religion as a major coping response to stress. Rodriguez-Galan, posited that the power of faith and prayer, communal experience and meaning and morality were main forms of coping [30]. Religious coping mechanisms decreased symptoms of depression among college students [31]. On the other hand, results of the study revealed that substance abuse was never used as a coping behavior by the respondents. This contradicted to Onyeizugbo, wherein alcohol substance abuse was a significant factor in the coping behavior of young men in Africa [32]. Several studies identified mental disengagement, denial, restraint, avoidance or behavioral disengagement, emotional disengagement or focus on and venting of emotion as common coping behaviors [33-35].

This current research found that the female gender has higher perceptions of stress compared to males. Female nursing students have an overall stress of $22.44+7.11$ (moderate stress) which concurs with the result of the regression analysis. This means that the female gender, among the other demographic variables, is positively associated with the perceived stress of the nursing students with a coefficient value of 3.633. Higher levels of coefficient value represent direct close associations. Monteiro posited that female students were more stressed compared to male students and used wishful thinking and problem-focused disengagement as a means of coping [35]. Women have more family-to-work conflict and less partner support [36]. This may imply that Saudi Arabia, having a patriarchal family structure, imposes more stress on their female kin especially those involved in academe. This is concurred by Bonneville-Roussy, where women in universities experienced higher levels of stress and mostly affected by disengagement-oriented coping [37].

Based from the results, among the demographic variables, a student who is married (Beta $=-8.324 ; p=.025)$ and enrolled as a regular (Beta $=-16.160 ; p=.015$ ) may prove to have a negative influence with coping. A negative coefficient value (Beta) indicates an inversely proportional outcome of the variables. This may imply that since the majority of the respondents were married and regular, they scored lesser in the COPE inventory. This may mean that single students and bridging program students may have better coping as compared to married and regular nursing students. However, Rottmann's study showed that couples cope with stress better and experience fewer depressive symptoms [38]. Further, Amirkhan and Auyeung posited that unmarried students tend to more avoidance coping than married ones [39]. On the other hand, students in the bridging nursing program were found to have better coping skills as in the study of Sandover, showing that graduate 
entry students preferred planned problem solving strategies in response to stress compared to undergraduate students who favored confrontive coping, distancing, escape avoidance and accepting responsibility as coping strategies [40].

\section{Conclusion}

Female gender can have an influence with the perceived stress of the nursing students. Moreover, married marital status and regular nursing program may have a high probability of affecting the coping mechanism of the nursing students negatively. To validate the conclusion, other factors such as clinical competence, self-esteem, time management abilities, family finances and quality of student life maybe sources of stress and can be considered in further assessing coping responses to stress in later studies. Further studies are recommended on other branches of education such as engineering, education and arts to evaluate similarity or contrast of results. Other stressassessment tools and coping-assessment tools maybe utilized by future researchers to further add to the literature. Additional studies can be done performing two assessments at two different points in time: before the stressful event and after the stressful event. Arabic version of the tools may be more appropriate in assessing Arab students. Lastly, stress management activities are of utmost importance to help Saudi nursing students respond to stress effectively and positively.

\section{Limitation}

This study solely relied on self-report data gathered from the nursing students. Another limitation of the study was that data was gathered at one point in time. A higher response rate more than $38 \%$ would be more conclusive. Further, the design used in the study was only cross-sectional. No triangulation of findings was adopted.

\section{Acknowledgment}

The author has no funding to report.

\section{Declaration}

The author declares no conflict of interest.

\section{References}

1. Shinde MB, Hiremath P. Stressors, level of stress and coping mechanism adopted by undergraduate nursing students. International Journal of Nursing Education. 2014;6(2):231233. Doi: 10.5958/0974-9357.2014.00640.0

2. Cheung T, Wong SY, Wong KY, Law LY, Ng K, Tong MT, et al. Depression, anxiety, and symptoms of stress among baccalaureate nursing students in Hong Kong: A cross-sectional study. Int J Environ Res Public Health. 2016;13(8):779. Doi: 10.3390/ijerph13080779

3. Goldstein DS, Kopin IJ. Adrenomedullary, adrenocortical, and sympathoneural responses to stressors: a meta-analysis. Endocr Regul. 2008;42(4):111-119.

4. Chipas A, Cordrey D, Floyd D, Grubbs L, Miller S, Tyre B. Stress: Perceptions, manifestations, and Coping Mechanisms of Student Registered Nurse Anesthetists. AANA J.
2012;80(4 Suppl):S49-55.

5. Neil Schneiderman, Gail Ironson, Scott D Siegel. Stress and Health: psychological, behavioral, and biological determinants. Annu Rev Clin Psychol. 2005;1:607-628.

6. Evans W, Kelly B. Pre-registration diploma student nurse stress and coping measures. Nurse Educ Today. 2004;24(6):473-482.

7. Flores-Torres IE, Alarcón EH, Jiménez EC, Amador MAV, Barrios DZ, Narváez YR, et al. Afrontamiento y adaptación en pacientes egresados de unidades de cuidado intensivo. Aquichan. Chía-Colombia. 2011;11(1):23-39.

8. Gibbons C, Dempster M, Moutray M. Stress, coping and satisfaction in nursing students. J Adv Nurs. 2011;67(3):62132.

9. Hirsch C, Barlem E, Tomaschewski-Barlem J, Lunardi V, de Oliveira A. Predictors of stress and coping strategies adopted by nursing students. Acta Paul Enferm. 2015;28(3):2249.

10. Prasad CV, Suresh A, Thomas DK, Pritty MK, Beebi S, Multazim $V$. The level of stress and coping mechanism adopted by I Year B.Sc. nursing students. Arch Med Health Sci. 2013;1(1):19-23.

11. Labrague LJ. Stress, stressors, and stress responses of student nurses in a government nursing school. Health Sci J. 2013;7(4):424-35.

12. Wolf L, Stidham AW, Ross R. Predictors of Stress and Coping Strategies of US Accelerated vs. Generic Baccalaureate Nursing Students: An Embedded Mixed Methods Study. Nurse Educ Today. 2015;35(1):201-205.

13. Pulido-Martos M, Augusto-Landa JM, Lopez-Zafra E. Sources of stress in nursing students: a systematic review of quantitative studies. Int Nurs Rev. 2012;59(1):15-25.

14. Rajesh Kumar N. Stress and coping strategies among nursing students. Nursing and Midwifery Research Journal . 2011;7(4):141-151.

15. Hamaideh $\mathrm{SH}, \mathrm{Al}-\mathrm{Omari} \mathrm{H}, \mathrm{Al}-\mathrm{Modallal} \mathrm{H}$. Nursing students' perceived stress and coping behaviors in clinical training in Saudi Arabia. J Ment Health. 2017;26(3):197-203.

16. Alsaqri SH. Stressors and Coping Strategies of the Saudi Nursing Students in the Clinical Training: A Cross-Sectional Study. Education Research International. 2017;2017:8. Doi: 10.1155/2017/4018470.

17. Almalki M, Fitzgerald G, Clark M. The nursing profession in Saudi Arabia: An overview. Int Nurs Rev. 2011;58(3):304-11. DOI: 10.1111/j.1466-7657.2011.00890.

18. Elzubeir MA, Elzubeir KE, Magzoub ME. Stress and coping strategies among Arab medical students: towards a research agenda. Educ Health (Abingdon). 2010;23(1): 355. 
19. Cohen S, Kamarch T, Mermelstein R. A global measure of perceived stress. J Health Soc Behav. 1983;24(4):385-396.

20. Lee EH. Review of the psychometric evidence of the perceived stress scale. Asian Nurs Res (Korean Soc Nurs Sci). 2012;6(4):121-127.

21. Chaaya M, Osman H, Naassan G, Mahfoud Z. Validation of the Arabic version of the Cohen perceived stress scale (PSS-10) among pregnant and postpartum women. BMC Psychiatry. 2010;10:111.

22. Cohen S, Williamson G. Perceived stress in a probability sample of the United States. In: S. Spacapan, S. Oskamp, editors. The social psychology of health: Claremont symposium on applied social psychology. Newbury Park, CA: Sage; 1988. p. 31-67.

23. Mitchell AM, Crane PA, Kim Y. Perceived stress in survivors of suicide: Psychometric properties of the perceived stress scale. Res Nurs Health. 2008;31(6):576-585.

24. Leung DY, Lam TH, Chan SS. Three versions of perceived stress scale: Validation in a sample of Chinese cardiac patients who smoke. BMC Public Health. 2010;10:513.

25. Wang Z, Chen J, Boyd JE, Zhang H, Jia X, Qiu J, et al. Psychometric properties of the Chinese version of the perceived stress scale in policewomen. PLoS One. 2011;6(12):e28610.

26. Carver CS. COPE Inventory. Measurement Instrument Database for the Social Science. 2013. Available from: www. midss.ie.

27. IBM Corp. Release. IBM SPSS Statistics for Windows, version 22.0 Armonk (NY): IBM Corp.;2013.

28. Saleh D, Camart N, Romo L. Predictors of Stress in College Students. Front Psychol. 2017;8:19. Doi: 10.3389/ fpsyg.2017.00019

29. Fang-Fang Z, Xiao-Ling L, Wei He, Yan-Hong G, Dong-Wen Li. The study of perceived stress, coping strategy and selfefficacy of Chinese undergraduate nursing students in clinical practice. Int J Nurs Pract. 2015;21(4):401-9. Doi. org/10.1111/ijn.12273.

30. Rodriguez-Galan M, Falcon L. Religion as a coping mechanism for health problems and depression among aging Puerto Ricans on the Mainland. J Relig Spiritual Aging. 2017;30(2):130-153. Doi: 10.1080/15528030.2017.1413031.

31. Areba EM, Duckett L, Robertson C, Savik K. Religious Coping, Symptoms of Depression and Anxiety, and Well-Being Among Somali College Students. J Relig Health. 2018;57(1):94-109. Doi: 10.1007/s10943-017-0359-3

32. Onyeizugbo E. Age, gender, and alcohol abuse as factors in coping behaviour. Nigerian Journal of Psychological Research. 2017;10:1.
33. Chou WP, Ko CH, Kaufman EA, Crowell SE, Hsiao RC, Wang $\mathrm{PW}$, et al. Association of stress coping strategies with Internet addiction in college students: The moderating effect of depression. Compr Psychiatry. 2015;62:27-33. Doi: 10.1016/j.comppsych.2015.06.004.

34. Na H, Dancy BL, Park C. College Student Engaging in Cyberbullying Victimization: Cognitive Appraisals, Coping Strategies, and Psychological Adjustments. Arch Psychiatr Nurs. 2015;29(3):155-61. Doi: 10.1016/j.apnu.2015.01.008.

35. Monteiro N, Balogun S, Oratile K. Managing stress: the influence of gender, age and emotion regulation on coping among university students in Botswana. Int J Adolesc Youth. 2014;19(2):153-173. Doi: 10.1080/02673843.2014.908784.

36. DePasquale N, Polenick C, Davis K, Moen P, Hammer LB, Almeida DM. The Psychosocial Implications of Managing Work and Family Caregiving Roles: Gender Differences Among Information Technology Professionals. Journal of Family Issues. 2015;38(11):1495-1519. Doi: 10.1177/0192513X15584680.

37. Bonneville-Roussy A, Evans P, Verner-Filion J, Vallerand R, Bouffard T. Motivation and coping with the stress of assessment: Gender differences in outcomes for university students. Contemporary Educational Psychology. 2017;48:2842. Doi: 10.1016/j.cedpsych.2016.08.003.

38. Rottmann N, Hansen D, Larsen P, Nicolaisen A, Flyger H, Johansen $C$, et al. Dyadic coping within couples dealing with breast cancer: A longitudinal, population-based study. Health Psychol. 2015;34(5):486-95.

39. Amirkhan J, Auyeung B. Coping with stress across the lifespan: Absolute vs. relative changes in strategy. J Appl Dev Psychol. 2007;28(4):298-317.

40. Sandover S, Jonas-Dwyer D, Marr T. Graduate entry and undergraduate medical students' study approaches, stress levels and ways of coping: a five year longitudinal study. BMC Med Educ. 2015;15:5. Doi: 10.1186/s12909-0150284-7. 